\title{
A Medical Student's Education in Addiction
}

\author{
Nadia Palma
}

Received: 16 October 2014 / Accepted: 22 October 2014 / Published online: 22 November 2014

(C) Academic Psychiatry 2014

The continued use of a substance despite the negative consequences it brings is a sine qua non for the definition of the disease of addiction. According to the American Society of Addiction Medicine, it is a chronic, relapsing disease that has biological, psychological, social, and spiritual consequences, in which an individual is unable to abstain from constantly using and pursuing the drug [1]. Like any other chronic condition, it is progressive and can result in an untimely death if left untreated. With so many dimensions of the individual being affected, it is appalling that only 1 in 10 patients who are suffering from addiction receive the proper treatment, whereas 7 in 10 people receive treatment for diseases like hypertension and diabetes. Moreover, there are currently 40 million Americans over the age of 12 that are currently addicted to nicotine, alcohol, or other drugs. This number is greater than all heart conditions, diabetes, or cancer [2].

Why then, does this epidemic not garner much more attention? Part of the issue is the fact that medical education systems do not properly equip future physicians with the tools to treat and recognize this disease [3]. While at most medical schools students receive very little education in substance use disorders, as a third year medical student, I was extremely fortunate to have been exposed to several lectures and relevant clinical experiences in the addiction field during my psychiatry rotation. I was able to see this disease in full-fledged form as well as in actively recovering individuals who had gotten their lives back. It was this particular patient population that subsequently inspired me to become a psychiatrist. However, despite all that I had learned and experienced, I was left wanting more.

To immerse myself in the world of addiction, I attended the Summer Institute for Medical Student program (SIMS) at the

\footnotetext{
N. Palma ( $\bowtie)$

University of Florida College of Medicine, Gainesville, FL, USA

e-mail: npalma@ufl.edu
}

Betty Ford Center at the beginning of my fourth year, in which medical students spend a week integrated into the lives of patients that are currently being treated at the center. I was assigned to the female inpatient unit. On my first day at the center, I was told I would attend group sessions with the same counselor every day for the rest of the week. This helped to foster continuity and familiarity among the participants. I was extremely curious to assess the dynamic in the group, as I had been to other AA meetings and group sessions before, but I had never been an active participant. After our morning meditation, I would attend my first group therapy session. Under the counselor's guidance, one by one, the women in the group began sharing their story and how they had gotten to the Betty Ford Center. Each story was different in that they all had different motives for drinking or using, but they all courageously admitted they were powerless before their condition. Gradually, as each one of them shared her story and the rest would provide feedback or explain how they related to the story they just heard, a group of formerly unfamiliar women had turned the room into a safe place for everyone, including me, to share personal experiences. Since the group was comprised by women who were in different stages in their recovery, I was able to witness how those who had spent more time at the center were able to guide the newcomers in expressing their feelings about past experiences, and in doing so, they were able to strengthen their own hopes for the future and their resolution to stay sober. It was during group therapy that I understood that a disease as complicated and multifaceted as addiction requires a multi-targeted approach rather than just medical treatment. We were doing more than exchanging past experiences in that room; we were rebuilding values and virtues and reshaping all of the qualities that addiction had mercilessly stripped away from our lives in different ways.

I was invited to share my own experience with addiction, and of course, I told the story about a man (see box). He was my uncle, and I was the oldest of the girls waiting for him at 
home. I was surprised at the candor with which I related my story - never before had I revealed all the details of that night. After this very emotional and therapeutic session, I realized I felt much more liberated about my experience as a child and was able to see my uncle as the witty, fast-talking man I held so dear once again. I had seen recovery, and I had been a part of it as well.

My experience at the Betty Ford Center changed the way I will practice medicine for the rest of my career. The lectures given by experts in the field helped me understand the neurobiology of addiction more clearly, but it was the testimony of the patients and staff that spoke to my heart and spirit. I witnessed a genuine attitudinal change taking place both inside the patients and me. Any misconceptions about addiction that I could have still been harboring were dismantled by these women's actions during my week with them. I encourage every medical student, regardless of their conceptions about addiction to learn about this disease as much as possible. Most medical school curricula still do not prepare medical students well to manage this ever more prevalent condition, so personal initiative is key [3]. The SIMS program is an excellent resource, but there are also AA, NA, and Al-Anon meetings open to visitors, where life-changing testimonies are exchanged daily around the country. There are also countless online resources that can be consulted. It is our responsibility to be familiar with addiction to better serve the needs of patients regardless of what specialty we ultimately choose.

Acknowledgments I wish to express my deepest gratitude to the Betty Ford Center patients and staff who gave me a life-changing experience as well as to Dr. Sarah Fayad for her guidance and support with this project.

\section{References}

1. American Society of Addiction Medicine. Public policy statement: definition of addiction. http://www.asam.org/research-treatment/ definition-of-addiction. Accessed August 23, 2014.

2. The National Center on Addiction and Substance Abuse at Columbia University. Addictione medicine: closing the gap between science and practice. http://www.casacolumbia.org/addiction-research/reports/ addiction-medicine. Accessed August 26, 2014.

3. Wood E, Samet JH, Volkow ND. Physician education in addiction medicine. JAMA. 2013;310(16):1-2.

He needed a place to stay for the next couple of days while the visa paperwork was ready, so why not visit his sister and her family? After all, it would be nice to see his nieces. He had not visited the capital since he dropped out of medical school, but he still knew the main roads well. He thought about picking up a few gifts for his nieces before heading to his sister's house, where a home cooked meal and three eager faces would be waiting for him. Suddenly, a tap on his left shoulder: it was an old college pal. "Very well, just one drink; I have to be home in time for dinner" he thought to himself. It was 11:00 pm and he had not come home. His sister was desperate. With tears streaming down her face, she continuously repeated aloud that he had promised he would stop drinking, which means something terrible must have happened to him. A few minutes later, he came stumbling through the front door, after fiddling with the lock for too long. The smell of beer and cigarettes permeated his clothing. "You had 15 beers in one night?" his sister said. He could feel the feelings of disappointment and regret mushrooming up in his chest as if he were back in medical school, and everyone thought it must have been a mistake that the most brilliant and promising student in the class was now failing. She continued ranting, and finally, he instinctively disgorged his anger on an innocent bystander, the housekeeper. Ashamed and afraid, he ran out the door. It was not long before his sister notified the police and he was taken into custody. He felt a familiar guilt about not measuring up to expectations and the same debilitating, lack of control over alcohol. 